Discussion Paper No. 03-35

\title{
Will the (German) NAIRU Please Stand up?
}

Wolfgang Franz

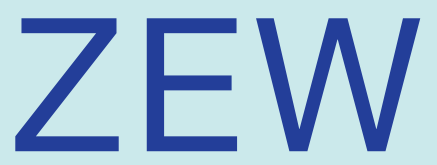

Zentrum für Europäische Wirtschaftsforschung GmbH

Centre for European Economic Research 
Discussion Paper No. 03-35

\title{
Will the (German) NAIRU Please Stand up?
}

\author{
Wolfgang Franz
}

Download this ZEW Discussion Paper from our ftp server:

\section{ftp://ftp.zew.de/pub/zew-docs/dp/dp0335.pdf}

Die Discussion Papers dienen einer möglichst schnellen Verbreitung von neueren Forschungsarbeiten des ZEW. Die Beiträge liegen in alleiniger Verantwortung der Autoren und stellen nicht notwendigerweise die Meinung des ZEW dar.

Discussion Papers are intended to make results of ZEW research promptly available to other economists in order to encourage discussion and suggestions for revisions. The authors are solely responsible for the contents which do not necessarily represent the opinion of the ZEW. 


\title{
Will the (German) NAIRU Please Stand up?
}

\author{
Wolfgang Franz ${ }^{1}$
}

\begin{abstract}
This paper deals with a critical assessment and a reestimation of the "non-accelerating inflation rate of unemployment" (NAIRU) for Germany. There are quite a few obstacles to perceiving the NAIRU as an understandable and easy-to-use analytical instrument, suitable for economic policy: the possibility of a non-vertical Phillips curve (e.g. in times of low inflation), the occurrence of shocks and hysteresis effects, the (mis-)measurement of important variables such as inflation expectations, cointegration issues, and a time variability of the NAIRU and its confidence intervals. Despite many serious caveats a new attempt is made to estimate a NAIRU for Germany based on conventional Phillips curves as well as on new approaches such as using direct measures of inflationary expectations, the Kalman filter method, and the residual-based bootstrap procedure (in order to estimate confidence intervals). However, by any method, simple or complex, the NAIRU is very hard to determine and subject to considerable arbitrariness.
\end{abstract}

JEL classification: C22, E24, E31

Key words: NAIRU, unemployment, inflation, Phillips curve, natural rate, hysteresis, supply shocks, inflation expectations, Kalman filter, bootstrap

Contact: Prof. Dr. Wolfgang Franz, Zentrum für Europäische Wirtschaftsforschung (Centre for European Economic Research, ZEW), P.O. Box 103443, D-68034 Mannheim, Germany. Tel.: 0049-621-1235-100. Fax: 0049-621-1235-222. Email: franz@zew.de. Homepage: www.zew.de.

\footnotetext{
${ }^{1}$ Center of European Economic Research (ZEW), Mannheim, University of Mannheim, Germany, and Council of Economic Experts. Very skillful research assistance by Marcus Kappler, Daniel Radowski, and Katrin Ullrich is gratefully acknowledged. Helpful comments by Jürgen Wolters (Berlin), François Laisney and Friedrich Heinemann (ZEW) as well as Stephan Kohns (Council of Economic Experts) improved the paper considerably. Regrettably, the usual disclaimer applies, of course.
} 


\section{Non-Technical Summary}

The "non-accelerating inflation rate of unemployment" (NAIRU) serves as the empirical counterpart of the unobserved "natural rate of unemployment". The NAIRU indicates a threshold figure of the unemployment rate: if the actually observed value of the unemployment rate is above the NAIRU, existing unemployment may decline not only on account of improved supply conditions but also due to an increase of goods demand without having to expect higher inflation rates. However, once the NAIRU threshold is attained, the situation is different: as long as inflation rates are to be kept stable, unemployment can only be fought by supply side measures which, for example, reduce a prevailing malfunctioning of the labor market. Hence, the NAIRU represents a rough borderline between a "deficiency-of-demand" component of unemployment and a "structural" part no matter how little meaning the latter adjective might have. Therefore, knowledge of the empirical NAIRU provides economic policy with useful information. These are the good news.

The bad news start with the recognition that by any method, simple or complex, the NAIRU is very hard to determine. Even worse, the whole NAIRU idea may be seriously damaged if the joint behavior of inflation, wage rises and unemployment has deteriorated. There are several obstacles to perceiving the NAIRU as an understandable and easy-to-use analytical instrument, suitable for economic policy: the treatment of supply shocks and the persistence of unemployment leaves room for questions and gives rise to quite a few different concepts of the NAIRU; in times of low inflation the Phillips curve which relates inflation to unemployment, may not be vertical as is required by the NAIRU idea; the measurement of various variables is subject to some arbitrariness but affects NAIRU estimates; also a matter of choice are important parameters for the estimation procedure of a time-varying NAIRU.

Despite serious doubts an attempt is made to estimate a "state of the art" NAIRU for Germany. At the risk of exaggerating the case: not very much of all applied procedures really worked. Unless the NAIRU is combined with other diagnostics of the economists' toolkit, the NAIRU cannot serve as a useful tool to frame policy discussions, given all the uncertainty surrounding its level and direction of change. 


\section{Contents}

1. Introduction

2. Basic Theoretical Model

3. The Phillips Curve: Vertical?

4. Shocks and Persistence Effects

5. Data and Econometric Issues

5.1 How to Measure Actual Inflation and Unemployment Rates?

5.2 Direct Measures of Inflation Expectations

5.3 Cointegration

5.4 Time Variability and Confidence Intervals

6. Estimation Results

7. Epilogue 
Economists should not have accepted the natural rate hypothesis so readily.

George A. Akerlof (2002)

I have become convinced that the NAIRU is a useful analytical concept.

Joseph E. Stiglitz (1997)

\section{Introduction}

The "non-accelerating inflation rate of unemployment" (NAIRU) comes bouncing back, thus supporting the view that creaking doors hang longest, or in the local saying, ideas or persons said to be dead live longest. The revival of the NAIRU can be observed both in academia and on the political stage as it is evidenced by numerous scholarly work published in prestigious journals since the midst of the nineties ${ }^{2}$ and by concomitant work in research departments of supranational institutions such as the European Central Bank or the European Commission which presumably will not lack any influence on policy making. ${ }^{3}$

Obviously, the rediscovery of the NAIRU raises the question on whether there is any substantial progress in understanding and estimating the NAIRU compared with its heydays some 15 years ago. Are NAIRU estimates more or less reliable today? Can the NAIRU still(?) serve as an instrument for policy advice? Should the idea of the NAIRU as the empirical counterpart to the natural unemployment rate still govern macroeconomic modeling and inform policy making?

The remainder of this paper is organized as follows. The next section provides a very brief outline of the theoretical framework of the NAIRU standard in the literature. Section 3 is devoted to the question as to whether the (short-run) Phillips curve is vertical or negatively sloped. Section 4 introduces supply shocks and persistence effects which give rise to a variety of NAIRU definitions and cloud the issues. Section 5 discusses at some length how to measure actual and expected inflation, respectively, and unemployment. Direct measures of inflation expectations are considered which will be used when estimating the Phillips curve. In addition, econometric issues such as cointegration and methods to estimate a time-varying NAIRU are the topics of sections 5.3 and 5.4, respectively, including a residual-based bootstrap method in order to estimate confidence intervals. Section 6 presents and discusses the estimation results including, with considerable courage, an estimated time-varying NAIRU for (West) Germany. Finally, section 7 concludes.

\footnotetext{
${ }^{2}$ Those papers range from the collection of writings in the spring issue of the Journal of Economic Perspectives 1997 up to more recent studies by Ball and Mankiw (2002), for example.

${ }^{3}$ See Fabiani and Mestre (2001) for an ECB discussion paper. Moreover, the EU commission in both of its reports on the "EU Economy 2002 Review" and "Employment in Europe 2002" refers (extensively) to NAIRU estimates.
} 


\section{Basic Theoretical Model}

The theoretical underpinnings of the NAIRU concept are well documented in the literature. ${ }^{4}$ Hence, it may suffice here to very briefly sketch an outline of its framework. The basic specification of the NAIRU refers to a descriptive reduced form of a price and wage equation such as:

$$
p_{t}=a(L) p_{t-1}-b(L)\left(U_{t}-U^{*}\right)+c(L) z_{t}+\varepsilon_{t} .
$$

In this notation lower-case letters designate first differences of logarithms. Hence, $p_{t}$ and $p_{t-1}$ represent current and lagged inflation rates, respectively, and $z_{t}$ is a vector including rates of changes of supply shift variables such as raw material prices and tax wedges. Upper-case letters indicate levels of variables, hence, $U_{t}$ and $U^{*}$ denote the current unemployment rate and a constant natural rate, respectively. The coefficients $a(L), b(L)$ and $c(L)$ are polynomials in the lag operator $L$, and $\varepsilon$ is a serially uncorrelated error term. Equation (1) incorporates informally Gordon's (1997) "triangle model" of the NAIRU: Influences stem from the demand side (via $U_{t}-U^{*}$ ), the supply side (via $z_{t}$ ), and from price rigidities (via $a(L) p_{t-1}$ ) and, perhaps even more important, from expected inflation (approximated by adaptive expectations, i.e., a distributed lag of observed inflation rates) which has taken center stage ever since the seminal Friedman-Phelps-hypothesis of the late 1960's. Note further that the supply shocks are assumed to be contemporaneously uncorrelated with unemployment.

If $a(1)=1$ the NAIRU can be calculated from equation (1) for stable inflation rates: ${ }^{5}$

$$
\mathrm{NAIRU}=U^{*}+c(1) z_{t} / b(1)
$$

In the absence of supply shocks (i.e., for $z=0$ ), the NAIRU equals $U^{*}$. For this case, an estimate of $U^{*}$ can be calculated from the intercept $d \equiv b(1) U^{*}$ of the following regression equation:

$$
p_{t}=d+a(L) p_{t-1}-b(L) U_{t}+\varepsilon_{t} .
$$

$U^{*}$ is referred to as the "no shock-NAIRU" (Franz and Gordon (1993)). It stands in contrast to a NAIRU concept which takes into account the presence of shocks $z \neq 0$. However, whether any increases of $p$ stemming from supply shocks, e.g. from higher indirect taxes, should be offset by, say, a restrictive monetary policy causing higher unemployment is open to disagreement.

Allowing for a time-varying NAIRU, $U^{*}$ is replaced by $U_{t}^{*}$ with the latter being described by a random walk with drift, for example:

\footnotetext{
${ }^{4}$ See e.g. Franz and Gordon (1993) and Richardson et al. (2000).

${ }^{5}$ Hence, the term NAIRU - an acronym anyway - is misleading due to a false use of calculus: The absence of a change of inflation is confused with "non-accelerating inflation", i.e. the first order of differentiation of inflation is confused with the second order.
} 


$$
U_{t}^{*}=U_{t-1}^{*}+\eta_{t}
$$

with $E\left(\eta_{t}\right)=0$ and $\operatorname{var}\left(\eta_{t}\right)=\sigma^{2}$. For $\sigma=0$ we obtain the constant NAIRU, whereas for $\sigma>0$ the NAIRU is subject to fluctuations. Such fluctuations can be the result of changing explanatory variables not included in equation (1). A time-varying NAIRU can also be driven from hysteresis phenomena such as a dequalification and disencouragement of (long-term) unemployed persons.

\section{The Phillips Curve: Vertical?}

The rationale for $a(1)=1$, i.e. the implication of a long-run vertical Phillips curve is based on the Friedman-Phelps-hypothesis of the late 1960's which claims that workers care about and bargain for real wage increases rather than nominal wage gains. In a situation when labor markets are very tight - unemployment is below the natural rate - workers demand and receive wage increases in excess of expected inflation (besides higher compensation due to, say, productivity progress). However, firms pass the associated cost increases into prices. Therefore the resulting inflation exceeds inflation initially anticipated in wage bargaining. As a consequence, with unemployment permanently falling short of the natural rate, inflation would accelerate. Conversely, holding unemployment above the natural rate causes accelerating deflation. Hence, constant inflation rates require unemployment to equal the natural rate, or the NAIRU as the empirical counterpart of the unobserved natural rate (thus neglecting some minor differences between both concepts). ${ }^{6}$ Based on this reasoning it was concluded that the coefficient associated with expected inflation - the latter being represented, as in equation (1), by lagged inflation rates - must be one.

There are two different although not mutually exclusive arguments of why this restriction may not necessarily hold. The first one can be traced back to Sargent (1971) who pointed out that the coefficient on lagged inflation may not be unity even in an accelerationist model of inflation as long as the process of generating inflation is stable (without a unit root). More precisely, if the assumption of adaptive expectations of the Fisher-Cagan-type for expected inflation $p_{t}^{*}$ holds, i.e.,

$$
p_{t}^{*}=\sum_{i=0}^{m} \nu_{i} p_{t-i}
$$

and the term under consideration in the Phillips curve (1) is written as

$$
p_{t}=a \sum_{i=0}^{m} \nu_{i} p_{t-i}+\ldots
$$

\footnotetext{
${ }^{6}$ The NAIRU may exceed the natural rate, for example, due to inconsistently high claims on national output by wage-setters and price-setters. An unemployment rate higher than the natural rate is then the mechanism to bring together both claims and, hence, stability of inflation. Another but related difference between both concepts is pointed out in Carlin and Soskice (1990), chapter 6.3.
} 
it becomes immediately clear that the sum of the $\nu_{i}$ 's must be unity in order to decide by inspection of the coefficient $a$ whether the Phillips curve is vertical $(a=1)$ or negatively sloped $(a<1)$. A sum of weights $\nu_{i}$ less than unity - so the argument put forward by Sargent (1971) - must not necessarily reflect incomplete projection of inflation but rather the view that inflation is stationary and its best forecast is an autoregressive process with a stable polynomial, not one where the coefficients sum to one. ${ }^{7}$

A second and perhaps (even) more convincing argument of why the controversial number in the Phillips curve may fall short of unity has been brought forward one year later by Eckstein and Brinner (1972), but was more or less forgotten afterwards and taken up more recently by Akerlof et al. (2000). ${ }^{8}$ The authors refer to "behavioral macroeconomics" and present two hypotheses on why at low inflation there may be a long-run trade-off between output and inflation. The first one is "pure Keynes": workers resist, and firms rarely impose, cuts in nominal pay. Both, low inflation and nominal wage rigidity, then form a major obstacle against a downward adjustment of real wages. ${ }^{9}$ On the other side, there may be a possible benefit of low inflation serving as a lubricant of labor market adjustment. ${ }^{10}$ With a little more inflation real wages can adjust (more rapidly) and aggregate unemployment falls. The other argument put forward by Akerlof et al. (2000) is based on the idea that because inflation is not salient when it is low, anticipated future changes in the price level are ignored in wage bargaining. Put differently, the crucial parameter under consideration in the Phillips curve represents a combined effect of how people form expectations and how they use them. At higher inflation, wage bargaining takes expected inflation into account and the Phillips curve may become vertical indeed. At low inflation, workers are (voluntarily) fooled, there is a negatively sloped Phillips curve.

While Akerlof et al. (2000) elaborate on a fairly sophisticated theory, the upshot of their hypothesis is that the coefficient in question depends on past inflation experience. ${ }^{11}$ This is a testable hypothesis. There are at least two groups of econometric methods which may be considered. The first is to let the data speak, i.e., to estimate the Phillips curve with a time-varying parameter (at least) of the coefficient associated with lagged inflation by either splitting the sample period between low inflation periods and high inflation periods, respectively, or by employing a general Kalman filter estimation which permits (all) the key Phillips curve parameters to vary. The second group is based on theoretical considerations and, following Akerlof et al. (2000), decomposes the coefficient associated with lagged inflation $a$ in two separate influences, i.e., $a \equiv 1-(1-\alpha)(1-\beta)$, where $(1-\alpha)$ denotes the fraction of all firms which ignore a fraction $(1-\beta)$ of expected inflation. Hence, if $\alpha=\beta=1$ we are back to the vertical Phillips curve. But with half a fraction of firms which ignore half of expected inflation, the coefficient $a$ amounts to 0.75 , or to 0.56 if "half" is replaced by "two thirds".

\footnotetext{
${ }^{7}$ See also Schreiber and Wolters (2002).

${ }^{8}$ The information on Eckstein and Brinner (1972) is taken from the paper by Akerlof et al. (2000). See also Akerlof (2002).

${ }^{9}$ See also Graham and Snower (2002) and Snower and Karanassou (2002). In their papers they show that the interaction between money growth and staggered nominal contracts may give rise to a long-run inflation-unemployment tradeoff.

${ }^{10}$ For an empirical study for Germany see Franz (1984).

${ }^{11}$ See the comment by A. Blinder on the paper by Akerlof et al. (2000), p. 55.
} 
Moreover, the coefficient $a$ has to be constrained to range between zero and one by, say, using a standard cumulative normal distribution.

A negatively sloped Phillips curve, if it exists, is of special interest because the traditional NAIRU concept breaks down. In the case $a<1$, inflation rates do not cancel out in equilibrium (i.e., for stable inflation rates) as it is required by the NAIRU concept. To see this, consider a simplified version of equation (3):

$$
p_{t}=d+a p_{t-1}-b U_{t}
$$

Stability of inflation rates requires $p_{t}=p_{t-1}=p$ and equation (7) changes to

$$
0=d-(1-a) p-b U_{t} .
$$

Solving for the unemployment rate yields

$$
U_{t}=d / b-[(1-a) / b] p .
$$

In words, if $a<1$, the unemployment rate consistent with stable inflation rates depends on the level of such a stable inflation rate. The more ambitious the aim of inflation stability is pursued, such as price level stability, i.e., $p=0$, the higher the unemployment rate necessary to achieve this goal. For the sake of avoiding additional confusion - see subsequent sections - one would probably resist to call that unemployment rate a NAIRU, too, but introducing a new term would have the same disadvantage. Anyway, one has to provide a figure for a certain inflation rate, in order to calculate the unemployment rate in equation (9). Maybe, a "tolerable inflation rate" of, say, 2 per cent p.a. is a plausible number. Such a figure is viewed as just consistent with price stability by the European Central Bank.

\section{Shocks and Persistence Effects}

Besides the possibility of a non-vertical Phillips curve which already renders the NAIRU concept somewhat dubious, if not meaningless, there are other obstacles to perceiving the NAIRU as an understandable and easy-to-use analytical instrument, suitable for economic policy. For the sake of clearness, we assume for a moment that the Phillips curve is vertical indeed, but will take up this issue later again.

Figure 1 contrasts annual values of the unemployment rate with the corresponding changes of inflation rates of consumer prices for the time period 1972 to 2002 (the period under estimation). The NAIRU, if it exists, is the value of that unemployment rate which has an ordinate value of zero. Apparently, the presumed NAIRU has shifted during the past three decades: While in the midst of the seventies an unemployment rate of around 2 per cent seems to be consistent with stable inflation rates, this figure 
amounts to roughly 6 per cent in the beginnings of the nineties and even 8 per cent ten years later. If so, what happened?

Figure 1: Change of inflation rates and unemployment in West Germany 1972 to 1991 and 1992 to 2002 in Germany.

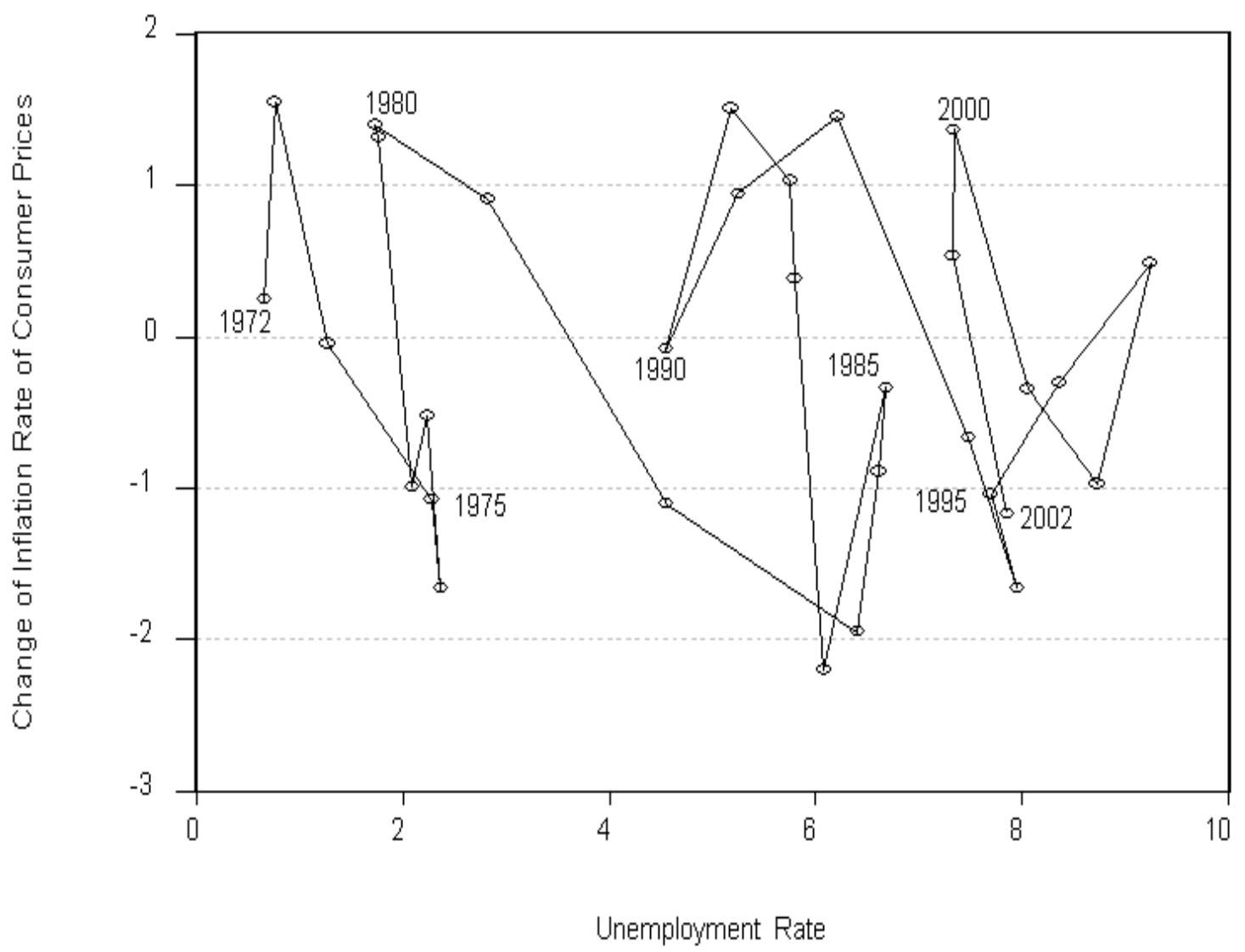

Sources: see notes at the bottom of table 1 .

The theoretical section touched upon two major sources of possible shifts of the NAIRU, shocks and hysteresis phenomena. To begin with shocks, included in the vector $z$, they can alter the rate of inflation at a given level of excess demand. No matter of the specific nature of these exogenous shocks, they give rise to a crucial distinction between a "shock-NAIRU" and a "no shock-NAIRU", depending on whether or not inflationary effects stemming from these shocks should be ironed out by higher unemployment. Put differently, in case of higher indirect taxes, for example, proponents of a no shock-concept would argue that the resulting transitory increase of inflation should be disregarded due to their character as self-inflicted wounds. On the other hand, opponents of that view would point out that "wounds are wounds" and should well increase the NAIRU. Hence, the NAIRU is subject to manipulation.

This verdict and the concomitant frustration with the NAIRU concept is strengthened in the presence of hysteresis phenomena. Referring to equation (4), the development of $U_{t}^{*}$ can be described more precisely by 


$$
\begin{gathered}
U_{t}^{*}=\bar{U}+\phi\left(U_{t-1}-\bar{U}\right)+\mu_{t} \\
\mu_{t} \sim N\left(0, \sigma_{\mu_{t}}^{2}\right) .
\end{gathered}
$$

In words, $U_{t}^{*}$ is now a "contemporaneous NAIRU", because of its time dependency, whereas $\bar{U}$ is the "steady-state NAIRU" or "equilibrium-NAIRU". Inserting equation (10) into equation (1) and rearranging terms yields ( $\Delta$ denotes the first difference operator):

$$
\begin{gathered}
p_{t}=a(L) p_{t-1}-b(L)\left[(1-\phi)\left(U_{t}-\bar{U}\right)+\phi \Delta U_{t}\right] \\
+c(L) z_{t}+\varepsilon_{t}+b(L) \mu_{t} .
\end{gathered}
$$

Three cases are of interest: ${ }^{12}$

(i) Full hysteresis: If $\phi=1$, then the "level effect" vanishes and there is no such thing like a unique NAIRU.

(ii) No hysteresis: If $\phi=0$, then the change term $\Delta U_{t}$ drops out and the pure Phillips curve mechanism works.

(iii) Persistence: If $0<\phi<1$, both the level and change effect of $U_{t}$ matter and the contemporaneous NAIRU can drift away from the steady state-NAIRU.

This distinction is not an artifact of the specification of the time path in equation (10) but holds for more generalized versions, too. ${ }^{13}$ More importantly, the consequences of hysteresis or persistence for the NAIRU are tremendous. A high level of unemployment today means a higher NAIRU tomorrow, or conversely, fighting successfully against unemployment today will partly avoid problems tomorrow. In methodological terms, in the presence of hysteresis or persistence there is a considerable risk of overestimating the NAIRU due to confusing the contemporaneous with the steady-state NAIRU.

In summing up the considerations in this section, we are left with a variety of NAIRUs: shock and no-shock ones on the one hand, contemporaneous and steady-state ones on the other. Whatever the merits of these distinctions, two contrary views emerge: Either the NAIRU concept impresses with a richness of facets or the NAIRU concept suffers from considerable "as you like it-choices" and is useless, therefore. It goes without saying that these two assessments fail to bring about consensus among economists.

\footnotetext{
${ }^{12}$ See also Franz (1987) and Franz and Gordon (1993).

${ }^{13}$ See Franz (2001), eqs. (13) and (14).
} 


\section{Data and Econometric Issues}

\subsection{How to Measure Actual Inflation and Unemployment Rates?}

Even the most simple version of a Phillips curve requires reflections on how to measure important variables such as inflation and unemployment. In addition, data problems stemming from German unification and revisions of national accounts and employment statistics, respectively, have to be taken into account. As will be shown below, each of the definitions under consideration exerts substantial influences on the NAIRU estimates.

To begin with inflation, both the use of consumer prices as well as the GDP deflator can be justified on theoretical grounds. This holds for the Phillips curve derived either from a non-structural approach, e.g. a reduced form of wage and price equations, or from a structural approach based on explicit models of labor demand and labor supply, respectively. ${ }^{14}$ For example, in a wage equation which reflects outcomes of wage bargaining, employers base their considerations on product wages, but employees on consumption wages. Product wages include employers' taxes on labor and contributions to social security and are deflated by sales prices, or, for the aggregate economy, by the GDP deflator for the private, non-agricultural sector (because prices in the governmental and agricultural sector are strongly regulated and, moreover, subject to somewhat erratic fluctuations). On the other hand, for employees and the unions the variable of interest in wage bargaining is the consumption wage, i.e., gross wages net of taxes and contributions to social security to be paid by employees and deflated by prices which represent costs of employees' living. Therefore, the estimations of the Phillips curve in the subsequent section will be based on both, the inflation rate of consumer prices as well as on the rate of change of the private, non-agricultural GDP deflator. In addition, whatever definition of inflation is used, we test the significance of a price and tax wedge variable, respectively. These variables have already been introduced in the vector $z$ in equation (1) as "supply shift variables" which can alter the rate of inflation at a given level of excess demand. By the same token, relative imported raw materials prices also constitute a supply shock as is evidenced by the two oil price shocks 1974 and 1982. The variable which will be used in the regressions below is the inflation rate of raw materials prices minus the inflation rate which corresponds with the dependent variable. Table 1 displays a summary statistic of these and other variables under consideration.

\footnotetext{
${ }^{14}$ See Franz and Gordon (1993) for both approaches.
} 
Table 1: Summary measures of inflation rates, unemployment rates and wedge variables $^{a)}$

\begin{tabular}{|c|c|c|c|c|c|c|c|c|}
\hline \multirow[t]{3}{*}{$\begin{array}{c}\text { Average over } \\
\text { interval }\end{array}$} & \multicolumn{2}{|c|}{$\begin{array}{l}\text { Inflation } \\
\text { rates p.a. }\end{array}$} & \multicolumn{2}{|c|}{$\begin{array}{l}\text { Inflation rates } \\
\text { of relative raw } \\
\text { material prices }\end{array}$} & \multirow[t]{2}{*}{$\begin{array}{c}\text { Tax } \\
\text { wedge }\end{array}$} & \multirow[t]{2}{*}{$\begin{array}{l}\text { Price } \\
\text { wedge }\end{array}$} & \multicolumn{2}{|c|}{$\begin{array}{l}\text { Unemploy- } \\
\text { ment rates }\end{array}$} \\
\hline & $\mathrm{p}^{G}$ & $\mathrm{p}^{C}$ & $\mathrm{p}^{R}-\mathrm{p}^{G}$ & $\mathrm{p}^{R}-\mathrm{p}^{C}$ & & & $\mathrm{U}^{N}$ & $\mathrm{U}^{S}$ \\
\hline & (1) & $(2)$ & (3) & (4) & $(5)$ & $(6)$ & (7) & $(8)$ \\
\hline $1970-1974$ & 6.64 & 5.72 & 10.68 & 11.60 & 1.57 & 1.03 & 1.04 & 0.57 \\
\hline 1975-1979 & 4.00 & 4.00 & 2.21 & 2.20 & 1.67 & 1.04 & 4.31 & 2.13 \\
\hline 1980-1984 & 3.83 & 4.18 & 7.52 & 7.17 & 1.73 & 1.06 & 7.10 & 4.56 \\
\hline 1985-1989 & 2.17 & 1.28 & -15.75 & -14.86 & 1.80 & 1.02 & 8.67 & 5.85 \\
\hline 1990-1994 & 3.70 & 3.65 & -6.90 & -6.85 & 1.78 & 1.00 & 8.59 & 6.34 \\
\hline 1995-1999 & 0.81 & 1.29 & 6.97 & 6.49 & 1.92 & 1.02 & 11.67 & 8.42 \\
\hline 1999-2002/2 & 1.46 & 2.07 & 0.47 & 0.15 & 1.91 & 1.05 & 10.51 & 7.40 \\
\hline
\end{tabular}

a: Notes by column number in parentheses. Numbered sources in brackets identified at the end of notes. Inflation rates in cols. (1)-(4) are quarter to quarter changes multiplied by 400 .

Columns: (1) Rate of change of GDP deflator of the private non-farm sector [2].

(2) Rate of change of consumer price index [2].

(3) Difference between rate of change of prices of imported raw materials and rate of change of GDP deflator of the private non-farm sector [2].

(4) Difference between rate of change of prices of imported raw materials and rate of change of consumer price index [2].

(5) Ratio of employer labor cost (including employers' contributions to social security) to employee net take home pay (excl. employees' taxes on labor and contributions to social security)(1991=100), [1].

(6) Ratio of consumer price index to GDP deflator of private non-farm sector $(1991=100),[1]$.

(7) Unemployment rate according to definition by the German Federal Labor Office [3].

(8) Unemployment rate according to definition by the International Labor Office [2].

Sources: [1] Deutsches Institut für Wirtschaftsforschung (DIW), Vierteljährliche Volkswirtschaftliche Gesamtrechnung, Berlin; www.diw.de/deutsch/service/datenservice/statfinder.

[2] Destatis (Statistisches Bundesamt); www.zr.destatis.de.

[3] Bundesanstalt für Arbeit; www1.arbeitsamt.de/hst/services/ statistik/detail/.

Calculations by the author. 
Parenthetically we note that all rates of change refer to one-quarter changes rather than to four quarter-changes. Otherwise, by using four-quarter overlapping changes, the dependent variable and the respective lagged endogenous variables on the right hand side of equation (1) would contain three one-quarter changes in common, leading $a(L)$ to be upward biased and to absorb much of the explanation that may be properly attributable to the other explanatory variables. It goes without saying that this procedure calls for seasonal adjustment which is carried out by 0,1 -variables, $S_{i}-S_{4}, i=1,2,3$, which level out over the year and ensure that the intercept of the equation, which is important for calculating the NAIRU (see equation (3)), is not subject to seasonal disturbances.

Unemployment is the second variable under consideration. Recall from the theoretical model that it is designed to capture the pressure stemming from the labor market in wage bargaining and, on the other hand, the respective situation on the product market in the price-setting process. Indeed, the whole NAIRU idea is that unemployment is a good measure of pressure in labor markets. Moreover, if the mechanism of tight labor markets causing rising wages will turn out not to be central to the inflation process, the NAIRU framework is seriously damaged. While the unemployment rate in the wage equation may properly capture excess supply on the labor market, it is doubtful whether this holds for a situation of excess labor demand which may be more adequately measured by vacancies. Moreover, the tightness of the product market may be better represented by the capacity utilization rate or detrended output rather than by the unemployment rate. Of course, unemployment and capacity utilization may be (closely) connected via Okun's law but empirical investigations of the Okun curve (as well as of the Beveridge curve which relates unemployment with vacancies) reveal somewhat unstable relationships, to say the least. ${ }^{15}$ For this reason, Franz and Gordon (1993) elaborated on a German "Mean-Utilization Rate of Unemployment" (MURU), i.e., the unemployment rate consistent with an average mean utilization rate (of 84.4 per cent of potential output during the time period 1962 to 1990). Obviously, to explain the sense of a MURU to policy makers and to the public is an even more demanding if not unsurmountable obstacle compared with the NAIRU. ${ }^{16}$

The next decision to make is whether we follow the definition of the unemployment rate used by the German Federal Labor Office (FLO) or the standardized unemployment rate along the recommendation by the International Labor Office (ILO). As is displayed in table 1 the difference between both rates is anything but negligible. According to the FLO-definition, a person is included in the unemployment statistics if he or she registers himself or herself as unemployed at the labor office, is currently working less than 15 hours per week and is at the labor office's disposal for a placement. In contrast, the ILO-definition allows the person to work only less than one hour per week, and requires that the person is actively searching for a job and is available for work within two weeks. As a matter of fact, the FLO-unemployment rate exceeds the ILO-version substantially (around 700,000 persons in 2002), which amounts roughly to a three percentage points difference between both unemployment rates. In what follows we shall employ both versions of an unemployment rate. To be sure, however, this does not solve the problem of how to take hidden unemployment into account.

\footnotetext{
${ }^{15}$ See Franz (1987) and Franz and Siebeck (1991).

${ }^{16}$ Moreover, experiments with estimated output gaps in the Phillips curve did not yield a substantial higher explanatory power. See Franz (2001).
} 
Although there is reason to consider it less a problem as long as hidden unemployment leaves wage bargaining unaffected, this conjecture may not (fully) hold for people being "employed" by means of active labor market policies or for short-term workers (converted into unemployed equivalents). Inclusion of these persons would increase the FLO-unemployment rate in 2000 again by roughly 600,000 persons. Given data limitations, we will not pursue this issue any further.

\subsection{Direct Measures of Inflation Expectations}

As has been highlighted in section 3 already, a major drawback of conventional Phillips curve estimates is the use of distributed lags of actual inflation rates as a proxy for inflation expectations. This procedure implies testing a combined hypothesis, namely to what extent inflation expectations contribute to an explanation of actual inflation rates, as claimed by the Phillips curve, and whether the proxy for inflation expectation corresponds with true expectations by the economic agents under consideration. Hence, the need for direct measures of inflation expectations is obvious but to meet this requirement is not. ${ }^{17}$

Basically, two types of direct measures of inflation expectations are available for Germany albeit for a limited time period. The first rests on asking consumers about their expectations for consumer prices, the second relies on a survey among professional forecasters. Both approaches have their merits and problems. At first glance, asking consumers directly seems to provide exactly the information desired. However, in the absence of a strong motivation of respondents to answer correctly, the reliability of those data may be questioned even if the sample is large. ${ }^{18}$ On the other hand, professional forecasters may handle the survey questions more seriously. But it is unclear whether their replies are unbiased at any point of time given potential strategic interests. Moreover, they are typically concerned with a broader coverage of goods rather than only with those applied by consumers. Finally, both types of measures are often qualitative in nature ("balance statistics"), i.e., proportions of respondents opting for different response categories. Therefore, these data have to be transformed into numerical values for expected inflation rates. Since this methodology is anything but straightforward and not innocuous to (strong) assumptions, in the end, one winds up with testing combined hypotheses again.

Under these caveats we employ the following two direct measures of inflation expectations. The first is the EC monthly survey which - for Germany - poses the following question to approximately 2500 consumers: "By comparison with what is happening now, do you think that in the next 12 months ... (1) there will be a more rapid increase in prices, (2) prices will increase at the same rate, (3) prices will increase at a slower rate, (4) prices will stay about the same or (5) prices will fall slightly?" Available time series of monthly balance statistics start in 1985. Quantitative estimates of the expected rates of inflation from these qualitative data can be obtained by us-

\footnotetext{
${ }^{17}$ See the studies by Akerlof et al. (2000) for the U.S. and by Driver et al. (2003) for the U.K. and the U.S.

${ }^{18}$ Note that accuracy of the forecasts is not the issue here as long as economic agents behave on the basis of their (false) forecasts.
} 
ing, for example, a modified Carlson and Parkin-methodology as it is carried out by Gerberding (2001). Her data form the basis of our estimates. ${ }^{19}$ In short, the central idea behind the approach by Carlson and Parkin (1975) is to interpret the share of respondents replying to each category as maximum likelihood estimates of areas under the density function of aggregate inflation expectations. ${ }^{20}$ The expected value of that density function represents the average inflation rate expected by survey respondents. In addition, respondents are asked to condition their replies on their perceptions of current inflation ("... what is happening now ..."). Gerberding (2001) assumes that respondents correctly perceive the actual rate of inflation at the time they form their expectations. While this assumption is not as innocuous as it may seem, given last year's misperceptions of inflation rates by consumers at least in Germany in due course of the introduction of the Euro, it seems plausible in other time periods of low inflation. ${ }^{21}$ So we stay with her approach.

A second measure of inflation expectations stems from responses by professional forecasters. For Germany, two sources are available. The private enterprise "Consensus Economics" surveys about 26 institutions in Germany (mostly banks and economic research institutes). Given the small number of respondents and high purchasing prices for these data, we refer to a questionnaire sent out monthly by the Centre of European Economic Research (ZEW) located in Mannheim, Germany. ${ }^{22}$ Since December 1991 around 350 experts at banks, insurance companies, and large industrial firms opt for the following response categories: "The inflation rate, covering the whole economy, will in the next six months (1) increase, (2) not change, (3) fall." ${ }^{23}$ The resulting balance statistics are then transformed by the ZEW into quantitative inflation rates by using the Carlson and Parkin-method described before. Both, raw data and estimated expected inflation rates are available free of charge from the ZEW. ${ }^{24}$

\subsection{Cointegration}

Conventional Phillips curve estimates in the spirit of equation (2) are subject to the criticism of a possible serious misspecification stemming from omitted considerations about cointegration issues. ${ }^{25}$ More precisely, when inflation and unemployment are cointegrated, i.e., the linear combination of their time series is stationary, a regression consisting entirely of differenced data will be misspecified and a regression consisting entirely of undifferenced data will omit important constraints. ${ }^{26}$

\footnotetext{
${ }^{19}$ We are grateful to C. Gerberding for providing us with her estimates of inflation expectations based on the EC survey for Germany. Note that these data do not represent official data approved by the Deutsche Bundesbank.

${ }^{20}$ The density function is assumed by Gerberding (2001) to be log-normal. See also Batchelor and Orr (1988) and Reckwerth (1997).

${ }^{21}$ See Forsells and Kenny (2002) for other approaches covering the Euro area.

${ }^{22}$ See the ZEW-Finanzmarktreport (monthly, in German) and the ZEW-news (quarterly, in English) for more information. Inflation expectations are published as the results of the ZEW Financial Market Test (ZEW Finanzmarkttest), see the ZEW homepage at www.zew.de.

${ }^{23}$ There is a fourth category: "no assessment" which is disregarded.

${ }^{24}$ Contact www.zew.de.

${ }^{25}$ See e.g. Schreiber and Wolters (2002).

${ }^{26}$ See Franz and Gordon (1993), p. 730.
} 
To begin with, an elaboration on this issue requires firstly an inspection of the order of integration of the time series under consideration. ${ }^{27}$ If inflation is stationary, then no vertical Phillips curve can exist; but there may be a short-run one. If inflation is $\mathrm{I}(1)$, the NAIRU conception may hold depending on whether unemployment is I(1). If inflation is $\mathrm{I}(1)$ and unemployment is also $\mathrm{I}(1)$, the outcome depends on whether cointegration exists between both variables. If so, then a long-run Phillips curve may exist. If not, there is no long-run Phillips curve, but there may be a short-run relationship and filtering out the persistent component of unemployment (which is unrelated to inflation) has some merits.

While these methodological considerations deserve attention, one should resist the temptation to place too much emphasis on them. The Phillips curve is not simply a relationship between inflation and unemployment but is augmented by several variables. Besides this, other variables, not included in the Phillips curve framework but important, may govern variables such as inflation which is influenced by the development of monetary aggregates. Similar arguments hold for unemployment. If so, the Phillips curve can be consistent with a variety of orders of integration which puts the above considerations into question. ${ }^{28}$ Moreover and strictly speaking, the unemployment rate cannot be I(1) since it is a bounded variable. However, it is often claimed that this property serves "as a useful approximation to reality within the bounds" (Schreiber and Wolters (2002), p. 6, fn. 4). For all practical purposes, I(1) is what ADF-tests display for the unemployment rate in (West) Germany. Even so, some scepticism remains about the appropriateness of such generalizations. If we stay with an unemployment rate of order I(1) nevertheless, the next relevant question is whether inflation has an order of integration of at least I(1). Again, I(1) is what ADF tests for Germany typically reveal (despite the high reputation of the Deutsche Bundesbank). Hence, a test for cointegration is in order. The most popular test is a residual-based cointegration test where the residuals from the static Phillips curve regression are taken in a second step to carry out an $\mathrm{ADF}$-type regression testing for a unit root in the residuals. In the presence of a unit root (this is the null hypothesis), i.e., in the absence of stationarity, absence of cointegration cannot be rejected.

\subsection{Time Variability and Confidence Intervals}

The "state of the art - NAIRU" is a time-varying NAIRU with estimated confidence intervals. ${ }^{29}$ The idea is that the economy may have experienced more kinds of shocks and changes of institutions, both influencing inflation and unemployment, than can be captured by the set of supply shock variables introduced into the regression. ${ }^{30}$ Despite the possible appropriateness of estimating a time-varying NAIRU, the major shortcoming is that, even if the estimation turns out to be successful (whatever that means), one is still left with the question as to which forces drive the NAIRU. Seen from this

\footnotetext{
${ }^{27}$ See Schreiber and Wolters (2002), pp. 5 for the following different cases.

${ }^{28}$ To some extent, however, $U_{t}^{*}$ may capture non-stationarity.

${ }^{29}$ See e.g. the studies by Ball and Mankiw (2002), Fabiani and Mestre (2001), Gordon (1997, 1998), Greenslade et al. (2003), Gruen, Pagan and Thompson (1999), Laubach (1999) and Staiger, Stock and Watson (1997a).

${ }^{30}$ See eq. (4) in section 2.
} 
point of view, estimating a time-varying NAIRU is data analysis.

Several methods to estimate a time-varying NAIRU have been applied in the literature. With no claim of providing a survey, a first methodology can be illustrated by inspecting equations (1) and (4) which are repeated for the sake of convenience and where $U^{*}$ is replaced by $U_{t}^{*}$ already:

$$
\begin{gathered}
p_{t}=a(L) p_{t-1}-b(L)\left(U_{t}-U_{t}^{*}\right)+c(L) z_{t}+\varepsilon_{t} \\
U_{t}^{*}=U_{t-1}^{*}+\eta_{t} \text { with } E \eta_{t}=0 \text { and } \operatorname{var}\left(\eta_{t}\right)=\sigma_{t}^{2} .
\end{gathered}
$$

When $\sigma_{t}$ is equal to zero the NAIRU is a constant, otherwise the NAIRU varies each quarter. If there is no limit on the ability of the NAIRU to fluctuate each time period, the time-varying NAIRU may jump up and down and soak up all the residual variation in the Phillips curve (12). Staiger, Stock and Watson (1997a) and Gordon (1997, 1998) allow a constant standard deviation term $\sigma$ to be estimated and base their estimates of a time-varying NAIRU on a thus estimated $\sigma$ and variants of it. This model is dubbed a "stochastic time-varying parameter regression model" which can be estimated using maximum likelihood (ML) methods.

A second approach has been proposed recently by Ball and Mankiw (2002). For $a(1) \equiv 1$ equation (12) can be written as

$$
U_{t}^{*}+c(L) / b(L) z_{t}=U_{t}+1 / b(L) \Delta p_{t}-\varepsilon_{t} / b(L)
$$

Neglecting $\varepsilon_{t}$, the right-hand side can be computed from the data if the value of $b(L)$ is known, i.e., taken from other sources. This yields an estimate of the left-hand side. Within this sum, $U_{t}^{*}$ represents the longer-term trends, and the other term is viewed as proportional to the shorter-term supply shocks. Using the standard Hodrick-Prescott filter the authors extract $U_{t}^{*}$ from $U_{t}^{*}+c(L) / b(L) z_{t}$. Obviously, the crucial point is to choose a value for $b(L)$ and the smoothing parameter in the HP filter.

As in other studies such as Franz (2003), Greenslade et al. (2003), and Laubach (1999), for example, the analysis presented in this paper rests on the Kalman filter technique. More specifically, equations (12) and (13) serve as the "state space-model", where equation (12) is the "measurement equation" and equation (13) is the "transition equation". ${ }^{31}$ Note, however, one possible inconsistency of this procedure. Equation (13) implies, strictly speaking, full hysteresis which may or may not hold. But an implementation of persistence, if present, in the transition equation is anything but straightforward, hence, the literature (implicitly) accepts such a potential inconsistency. The state space-model defines a recursive Kalman filter from which a ML-estimator can be derived. To put it precisely, the time-varying intercept $b(L) U_{t}^{*}$ will be estimated with all other regression coefficients treated as constants. The estimated term $b(L) U_{t}^{*}$

\footnotetext{
${ }^{31}$ See Harvey (1983), pp. 82 for details. Strictly speaking, however, a state-space model involves only two points of time. This holds for equation (13) but for equation (12) only if $a(L)=a$.
} 
is then divided by the estimated constant coefficient of $U_{t}$, i.e., $b(L) \equiv b$. This yields a time-varying NAIRU $U_{t}^{*}$.

It is clear that this procedure is subject to several limitations and crucial assumptions. Some of them have been mentioned before. Moreover, an application of the Kalmanfilter requires to determine the initial conditions and the smoothing parameter. The initial state is estimated on the basis of the observations themselves, where a time period of four years before the sample period seems to be sufficient to obtain the required initial parameter values. With respect to the smoothing procedure it seems reasonable to argue that a "no-shock NAIRU", where supply shocks are ironed out, should not jump up and down each quarter. This holds especially if the NAIRU is viewed as the empirical counterpart of Friedman's natural rate. ${ }^{32}$ No matter how smoothing is carried out its arbitrariness is obvious. The procedure applied in this paper follows the method of estimating hyperparameters in a state space model described in Harvey (1993, pp. 91). In simple terms, from the hyperparameters only the intercept will be reestimated step by step, whereas $\sigma_{t}^{2}$ is determined exogenously and is not optimized within the ML-estimation procedure. ${ }^{33}$ The parameters are estimated on the basis of a prediction equation as well as of a backward recursion where the latter is based on the method of "fixed interval smoothing" which, according to Harvey (1993, p. 87), tends to be the most widely used algorithm for economic data. ${ }^{34}$

Nevertheless, the adopted Kalman-approach is fairly restrictive, particularly, because it inevitably produces a smoother NAIRU. As an alternative to the Kalman-method we therefore make use of an estimation procedure suggested by Schlicht (2003). His approach departs from the Kalman-technique, firstly, by using all past, present, and future observations for estimating each regression coefficient rather than only the past and the present observations as in the Kalman-filtering. To put it differently, the Schlicht procedure employs a two-sided filter, whereas the Kalman-filter relies on a one-sided filter. The justification for a two-sided filter is that all changes of the coefficients are data driven and not induced by the structure of the model, i.e., the current state of coefficients is correlated with future states. Hence, it would be inefficient to use a one-sided filter. Secondly, the estimation of variances is based on a general method of moments (GMM)-procedure rather than on a ML-estimation. The variances are selected under the assumption that the postulated variances are close to the true variances.

The second issue concerns confidence intervals for the NAIRU in order to display the amount of (im-)precision of estimated NAIRUs. The calculation of confidence intervals is not straightforward because the NAIRU is a nonlinear function of regression coefficients due to the intercept divided by $b(L)$. Staiger, Stock and Watson (1997a) use the "delta method" and "Fieller's method", respectively, for constructing confidence intervals. The "delta method" approximates the nonlinear function by using a firstorder Taylor series expansion and computes standard errors based on estimated first derivatives. In applying "Fieller's method" to the NAIRU, the authors first select a trial value of the NAIRU, insert this expression into the regression equation to be estimated, and check whether its estimated intercept is statistically insignificant. If so,

\footnotetext{
${ }^{32}$ See Gordon (1997), p. 22.

${ }^{33}$ Note that $\sigma_{t}^{2}$ is a scalar in our case in contrast to a matrix in the general case.

${ }^{34}$ See Harvey (1993), pp. 87 for details which cannot presented here due to a lack of space.
} 
they do not reject the hypothesis that the NAIRU amounts to that initial value and lies in a, say, 95 per cent confidence interval. Repeating this procedure for all possible values of the NAIRU produces the confidence interval. ${ }^{35}$

In this study we employ a residual-based bootstrap for calculating confidence intervals. Based on Franz (2001), to the best of our knowledge this is a novelty in the literature on the NAIRU although it is obvious to choose this method. The procedure goes as follows. ${ }^{36}$ From the estimated residuals of the Kalman-equation samples are drawn (with replacement) and inserted into the Kalman equation again. This yields new albeit artificial observations, dubbed resamples, with the help of which new values of the dependent variables are generated ("bootstrap replications"). Confidence intervals are then obtained from the variance of the NAIRU estimated by using the resamples. In order to solve the problem associated with the existence of a distributed lag of inflation rates, the initial values for the bootstrap data set are estimated by calculating for each resample new values for the lagged inflation rates using OLS estimates and inserting these values into the Kalman-equation.

\section{Estimation Results}

All estimates are based on quarterly data covering the time period $1972 / 1$ to $2002 / 2$ unless stated otherwise. Until 1990/4 the data refer to West Germany, afterwards to Germany. The corresponding structural break, if significant on the basis of a Chow test, is captured by an impulse dummy for 1991/1. This dummy should also take into account various changes in the national accounts data definitions in due course of the introduction of the European System of National and Regional Accounts 1995. All data according to the new definition are available since 1991/1, too; hence, this quarter serves as the respective breakpoint (in addition to effects due to unification). The data sources for all variables are listed in the notes to table 1. All quarterly change variables are defined in per cent as quarter-to-quarter change rates times 400 . Seasonal dummies are centered, i.e., $\left(S_{i}-S_{4}\right), i=1,2,3$, and therefore level out over the year.

As has been discussed in section 5.3 an assessment of time series properties of inflation and unemployment is in order. To begin with unit root tests, they obey the following one-step specification: ${ }^{37}$

$$
\begin{gathered}
\Delta x_{t}=(\rho-1) x_{t-1}+\sum_{k=1}^{7} \alpha_{k} \Delta x_{t-k}+\sum_{k=0}^{7} \beta_{k} D 91_{t-k} \\
+\gamma S D 91_{t-1}+\text { seasonal dummies }+ \text { constant }+ \text { time trend }+ \text { residuals },
\end{gathered}
$$

\footnotetext{
${ }^{35}$ See Staiger, Stock and Watson (1997b) for an application of this method to the estimation of a NAIRU for the U.S.

${ }^{36}$ See Efron (1982).

${ }^{37}$ The test procedures are similar to those adopted in Schreiber and Wolters (2002). Although some of our results resemble theirs, other differ due to different variable definitions and sample periods. The upper limits of summations are chosen arbitrarily but the results did not change more than negligible when we altered those figures.
} 
where $x_{t}$ denotes inflation and unemployment, respectively, D91 is an impulse dummy $(1991 / 1=1,0$ otherwise) and SD91 stands for a step dummy $(1991 / 1-2002 / 2=1$, 0 otherwise). Table 2 presents the results of this ADF-test for the inflation rate of consumer prices and the unemployment rate (according to definition by ILO), respectively. ${ }^{38}$ By inspection of the term $\rho-1$ it can be seen that the null hypothesis $\rho-1=0$, and, hence, $\rho=1$, cannot be rejected. Note that the critical MacKinnon - values are chosen by treating the step dummy as an additional I(1)-regressor. ${ }^{39}$ From these results we conclude that both variables can be possibly described by I(1) processes although the caveats expressed in section 5.3 still hold. Note further that relative inflation rates of imported raw materials prices and the change rate of the tax-price-wedge are both $\mathrm{I}(0)$.

Table 2: Univariate unit root tests for inflation and unemployment

\begin{tabular}{|l|c|c|}
\hline & Inflation & Unemployment \\
\hline$\rho-1$ (t-statistic) & $-0.428(3.3)$ & $-0.009(1.5)$ \\
Critical values $1 / 5 / 10$ percent & $-4.33 /-3.78 /-3.50$ & $-3.90 /-3.34 /-3.05$ \\
\hline Linear time trend & yes & no \\
Constant & yes & yes \\
Impulse dummy & yes & yes \\
Step dummy & yes & yes \\
Seasonal dummies $\mathrm{S}_{i}-\mathrm{S}_{4}$ & yes & yes \\
\hline$R^{2}$ adj. & 0.68 & 0.92 \\
Normality (Jarque-Bera) & 0.13 & 0.13 \\
LM 1-8 & 0.52 & 0.27 \\
LM 1-4 & 0.90 & 0.12 \\
Number of observations & 131 & 118 \\
\hline
\end{tabular}

The next relevant question is whether both variables cointegrate (see section 5.3). Since results turn out to be rather mixed we carry out two procedures, namely a residual-based cointegration test and a cointegration test in an error correction inflation equation. ${ }^{40}$ With respect to the residual-based cointegration test the results crucially depend on how many lagged differences enter the unit root tests. For example, the selection of the number of lagged differences can be based on, say, the Akaike and Schwarz criterion, respectively, where from the first criterion cointegration is rejected, but not from the second one. On the other hand, using an error correction inflation equation of the type (recall that $p$ is the inflation rate, $U_{t}$ the unemployment rate, and $z_{t}$ a vector including change rates of supply shift variables)

$$
\Delta p_{t}=\alpha_{1} p_{t-1}+\alpha_{2} U_{t-1}+\alpha_{3} z_{t-1}+\sum_{i=1}^{7} \beta_{i} \Delta p_{t-i}
$$

\footnotetext{
${ }^{38}$ See notes to table 3 for an explanation of diagnostic tests.

${ }^{39}$ See Hassler (2002) for suggesting such a procedure.

${ }^{40}$ Again we follow the procedure put forward by Schreiber and Wolters (2002).
} 


$$
\begin{gathered}
+\sum_{i=1}^{7} \gamma_{i} \Delta U_{t-i}+\sum_{i=1}^{7} \delta_{i} D 91_{t-i}+\alpha_{4} S D 91_{t-1} \\
+ \text { seasonal dummies }+ \text { constant }+ \text { time trend }+ \text { residuals }
\end{gathered}
$$

the relevant coefficient $\alpha_{1}$ ranges between -0.98 (4.1) and -0.79 (6.2) depending on which specification is used. Compared with the critical Banerjee-values for $1 / 5 / 10$ per cent significance of -3.78/-3.19/-2.89 (without time trend) and -4.27/-3.69/-3.39 (with time trend), cointegration cannot be rejected (the null hypothesis of the Banerjee-test is: inflation and unemployment are not cointegrated). 
Table 3: Estimated Phillips curves for(West)Germany 1972/1 to 2002/2 ${ }^{a}$ )

\begin{tabular}{|c|c|c|c|c|c|c|c|}
\hline \multirow[b]{2}{*}{ Explanatory variables } & \multirow[b]{2}{*}{ Lags } & \multicolumn{6}{|c|}{ Dependent variable } \\
\hline & & $\begin{array}{l}\mathrm{p}^{c} \\
(1)\end{array}$ & $\begin{array}{l}\mathrm{p}^{c} \\
(2)\end{array}$ & $\begin{array}{l}\mathrm{p}^{c} \\
(3)\end{array}$ & $\begin{array}{l}\mathrm{p}^{c} \\
(4)\end{array}$ & $\begin{array}{c}\mathrm{p}^{c d)} \\
(5)\end{array}$ & $\begin{array}{l}\mathrm{p}^{G} \\
(6)\end{array}$ \\
\hline Inflation rates ${ }^{b)}$ & $1-6$ & $\begin{array}{l}0.54 \\
(1.9)\end{array}$ & $\begin{array}{l}0.49 \\
(1.8)\end{array}$ & $\begin{array}{l}0.56 \\
(2.3)\end{array}$ & $\begin{array}{l}0.22 \\
(1.1)\end{array}$ & $\begin{array}{l}0.51 \\
(3.3)\end{array}$ & $\begin{array}{l}0.21 \\
(6.1)\end{array}$ \\
\hline Unemployment rate (ILO) & 1 & $\begin{array}{l}-0.28 \\
(3.2)\end{array}$ & $\begin{array}{c}-0.26^{c)} \\
(3.7)\end{array}$ & $\begin{array}{l}-0.59 \\
(3.7)\end{array}$ & $\begin{array}{l}-1.04 \\
(3.2)\end{array}$ & $\begin{array}{l}-0.29 \\
(4.0)\end{array}$ & $\begin{array}{c}-0.44 \\
(3.6)\end{array}$ \\
\hline $\begin{array}{l}\text { Change of unemployment } \\
\text { rates (ILO) }\end{array}$ & $1-8$ & $\begin{array}{l}- \\
-\end{array}$ & $\begin{array}{l}- \\
-\end{array}$ & $\begin{array}{l}- \\
-\end{array}$ & $\begin{array}{l}4.57 \\
(2.7)\end{array}$ & - & $\begin{array}{l}- \\
-\end{array}$ \\
\hline $\begin{array}{l}\text { Relative inflation of } \\
\text { imported raw materials }\end{array}$ & 0 & $\begin{array}{l}0.01 \\
(3.1)\end{array}$ & $\begin{array}{l}0.01) \\
(3.0)\end{array}$ & $\begin{array}{l}0.01 \\
(2.7)\end{array}$ & $\begin{array}{r}0.01 \\
(2.7)\end{array}$ & $\begin{array}{l}0.01 \\
(2.2)\end{array}$ & - \\
\hline $\begin{array}{l}\text { Change rate of } \\
\text { tax and price wedge }\end{array}$ & 0 & $\begin{array}{l}0.09 \\
(3.4)\end{array}$ & $\begin{array}{l}0.08 \\
(3.2)\end{array}$ & $\begin{array}{l}0.09 \\
(3.4)\end{array}$ & $\begin{array}{l}0.06 \\
(2.4)\end{array}$ & $\begin{array}{c}0.2 \\
(6.7)\end{array}$ & - \\
\hline Time trend & - & - & - & $\begin{array}{l}0.03 \\
(2.3)\end{array}$ & $\begin{array}{l}0.05 \\
(2.6)\end{array}$ & - & - \\
\hline Constant & - & $\begin{array}{l}2.65 \\
(3.5)\end{array}$ & $\begin{array}{l}3.44 \\
(4.0)\end{array}$ & $\begin{array}{l}2.68 \\
(3.6)\end{array}$ & $\begin{array}{l}4.49 \\
(3.6)\end{array}$ & $\begin{array}{l}2.73 \\
(4.2)\end{array}$ & $\begin{array}{l}4.68 \\
(4.1)\end{array}$ \\
\hline$R^{2}$ adj. & & 0.64 & 0.65 & 0.65 & 0.68 & 0.65 & 0.69 \\
\hline SSR & & 318 & 317 & 308 & 257 & 245 & 591 \\
\hline White & & $\begin{array}{r}24.32 \\
(0.6)\end{array}$ & $\begin{array}{c}22.78 \\
(0.6)\end{array}$ & $\begin{array}{c}26.61 \\
(0.5)\end{array}$ & $\begin{array}{l}65.54 \\
(0.01)\end{array}$ & $\begin{array}{c}20.25 \\
(0.4)\end{array}$ & $\begin{array}{c}24.60 \\
(0.3)\end{array}$ \\
\hline $\operatorname{LM}(4)$ & & $\begin{array}{c}7.93 \\
(0.09)\end{array}$ & $\begin{array}{c}6.05 \\
(0.20)\end{array}$ & $\begin{array}{c}4.77 \\
(0.31)\end{array}$ & $\begin{array}{c}3.25 \\
(0.52)\end{array}$ & $\begin{array}{c}0.76 \\
(0.94)\end{array}$ & $\begin{array}{c}6.83 \\
(0.15)\end{array}$ \\
\hline $\operatorname{LM}(8)$ & & $\begin{array}{l}11.15 \\
(0.19)\end{array}$ & $\begin{array}{l}10.03 \\
(0.26)\end{array}$ & $\begin{array}{c}8.21 \\
(0.41)\end{array}$ & $\begin{array}{c}7.81 \\
(0.45)\end{array}$ & $\begin{array}{l}11.48 \\
(0.18)\end{array}$ & $\begin{array}{l}10.21 \\
(0.25)\end{array}$ \\
\hline Normality & & $\begin{array}{l}22.38 \\
(0.00)\end{array}$ & $\begin{array}{c}19.08 \\
(0.00)\end{array}$ & $\begin{array}{c}14.44 \\
(0.00)\end{array}$ & $\begin{array}{c}3.02 \\
(0.22)\end{array}$ & $\begin{array}{c}33.89 \\
(0.00)\end{array}$ & $\begin{array}{l}14.96 \\
(0.00)\end{array}$ \\
\hline
\end{tabular}

Notes:

a) All regressions contain centered seasonal dummies with different regression coefficients for the period 1972/2-1982/4 and 1983/1-2002/2, respectively. Regressions allow for a dummy variable (if significant), which equals one for 1991/1 and is zero otherwise, and takes shifts due to national accounts data revisions and unification into account. All quarterly change variables are defined as relative quarter-to-quarter changes in per cent times 400. The estimations have been carried out by using the program package EViews 4.1. $t$-values in brackets below coefficients, $R^{2}$ adj. is the square of the correlation coefficient corrected for degrees of freedom; SSR denotes sum of squared residuals; "White" means test for heteroscedasticity in residuals, $p$-values in brackets $\left(H_{0}: \sigma_{t}^{2}=\sigma^{2}\right.$ for all $\left.t\right) ; \operatorname{LM}(x)$ is the Lagrange-Multiplier test for autocorrelation up to order $x, p$-values in brackets. "Normality" is the Jarque-Bera-test, $p$-values in brackets $\left(H_{0}:\right.$ normal distributions of residuals).

b) Sum of coefficients, highest $t$-value of all coefficients in brackets.

c) Unemployment rates according to definition by the German Federal Labor Office.

d) All variables are seasonally adjusted using the additive census $X 12$ method.

Estimates of an augmented Phillips curve are displayed in table 3 and can be summarized as follows:

(i) As long as inflation rates refer to consumer prices an augmented Phillips curve 
can be established with the relative inflation rates of imported raw materials and the rate of change of the tax and price wedge as supply shock variables (columns (1)-(5)). Roughly two thirds of the variance of the inflation rate can be explained. If, however, the rate of change of the GDP deflator forms the basis of the Phillips curve both supply shock variables lack significance (column (6)).

(ii) Both definitions of the unemployment rate are significant with a highly significant coefficient of nearly -0.3 in the short-run and around -0.6 in the long-run (columns (1) and (2)). This order of magnitude is roughly similar to estimates for the U.S. ${ }^{41}$ In order to allow for international comparisons of NAIRU estimates the ILO definition is referred to in further discussions unless stated otherwise.

(iii) Both the lagged unemployment rate and its lagged changes yield significant results (column (4)). Hence, strong hysteresis may be rejected but not persistence. The sum of coefficients of lagged inflation rates, however, decreases substantially and looses much of its significance.

(iv) A time trend variable is significant (columns (3) and (4)). A similar result is obtained if we allow the coefficient of the unemployment rate to vary between time subperiods. It decreases for more recent time periods, i.e., a NAIRU according to equation (3) would increase over time.

(v) The coefficient associated with the sum of lagged inflation rate is well below unity in all estimated Phillips curves. In order to make sure that this result is not an artifact of the use of seasonally unadjusted variables (together with centered seasonal dummies) column (5) reestimates the Phillips curve in column (1) using seasonally adjusted variables by employing the census X12 additive method. This leaves the coefficient in question virtually unaffected but increases the importance as well as the significance of the wedge variable.

(vi) The $R^{2}$ shows that roughly two thirds of the inflation rate can be explained by the explanatory variables. This is not an overwhelming contribution. Moreover, regressions are plagued by either non-normality or heteroscedasticity.

Taken at face value, the most disturbing issue for the NAIRU is the result described in paragraph (v), i.e., the coefficient of the sum of lagged inflation rates being much less than unity. While this result fits with previous studies of ours ${ }^{42}$ and with those of others such as Schreiber and Wolters (2002), who base their conclusions on a very sophisticated time series analysis, it simply means that, strictly speaking, there is no such a thing like a vertical Phillips curve. Put differently, these findings render the conventional NAIRU problematic, to say the least.

But before embarking on a swansong on the NAIRU one has to recall that the preceding econometric analysis suffers from various shortcomings. Besides several questionable details, the two most important doubts on the above estimates stem, firstly, from the treatment of expectations as adaptive, i.e., using distributed lags of actual inflation

\footnotetext{
${ }^{41}$ See the papers by Gordon (1998, table 3, p. 315; 1997, table 1, p. 25) and Stiglitz (1997), p. 5.

${ }^{42}$ See Franz $(2001,2003)$.
} 
rates rather than direct measures of inflation expectations, ${ }^{43}$ and, secondly, from neglecting near-rationality in periods of low inflation. We now address these two issues in turn.

Two variants of direct measures of inflation expectations are used which have been displayed in section 5.2, namely consumers' expectations based on the EC survey and expectations formed by experts as published by the ZEW financial market test. The availability of both series is restricted and, hence, the estimations cover the time period $1987 / 1$ to $2000 / 4$ and $1992 / 1$ to $2002 / 2$, respectively. Note further that the consumers' expectations cover a time period one year ahead whereas the ZEW's expectations measure includes a six-months time horizon. Moreover, there is a slight inconsistency with our measure of inflation rates as quarter-to-quarter changes (times 400), since both inflation rates are defined as annual rates (times 100).

Table 4 compares estimates of the Phillips curve on the basis of distributed lags of actual inflation rates (adaptive expectations) with both alternative direct measures of inflation expectations. Recall that the ZEW figures refer to the whole economy, hence, the rate of change of the GDP deflator serves as the dependent variable. Leaving aside all caveats mentioned before and replacing adaptive expectations by direct measures of inflation expectations pushes up the coefficient associated with the latter variables to a non-negligible extent. Clearly, a coefficient of 1.14 does not make much sense and has to be restricted to a value of one. ${ }^{44}$ Column (3) of table 4 displays the results of such a constrained regression which does not change much otherwise compared with column (2). The coefficient of the unemployment rate suffers from a loss of strong significance in all equations using direct measures of inflation expectations.

To dismiss adaptive expectations may be a conclusion too rash and broad-brush. Both, parts of firms as well as of wage bargaining parties may rely on backward looking adaptive expectations, whereas for the other parts expectations according to direct measures may hold. Moreover, recall from equation (1) that lagged actual inflation rates should capture price rigidities, too. Therefore, both explicit inflation expectations $p^{*}$ as well as lagged inflation rates, may enter the Phillips curve. Adding a lag distribution of actual inflation rates, however, turned out to be a complete failure whatever lag lengths are chosen. The corresponding coefficients had a (mostly significant) negative sign and the coefficient associated with expected inflation jumped up pointing to heavy multicollinearity between all these variables. From an economic viewpoint this unsuccessful attempt is strange against the background of empirical findings which support strong wage and price rigidities in Germany for reasons whatsoever. ${ }^{45}$

\footnotetext{
${ }^{43}$ Recall, however, that from eq. (1) lagged actual inflation rates should also capture price rigidities.

${ }^{44}$ In other versions of this equation the coefficient in question was estimated to lie around 0.9.

${ }^{45}$ See Franz and Pfeiffer (2002) for an empirical study of wage rigidities using survey evidence from German and US firms.
} 
Table 4: Phillips curve estimates with direct measures of inflation expectations

\begin{tabular}{|l|c|c|c|c|c|c|}
\hline \multirow{2}{*}{ Explanatory variables } & \multirow{2}{*}{ Lags } & \multicolumn{5}{|c|}{ Dependent variable and sample period } \\
\cline { 3 - 7 } & & $\mathrm{p}^{c}: 1987 / 1-2000 / 4$ & $\mathrm{p}^{G}: 1992 / 1-2002 / 2$ \\
\cline { 3 - 7 } & & $(1)$ & $(2)$ & $(3)$ & $(4)$ & $(5)$ \\
\hline Past inflation rates & & 0.65 & - & - & 0.45 & - \\
Expected inflation rates & - & - & 1.14 & 1.00 & - & 0.69 \\
& & & $(6.4)$ & $(-)$ & & $(1.9)$ \\
Unemployment rate (ILO) & \multirow{2}{*}{1} & -0.42 & -0.18 & -0.22 & -0.42 & -0.56 \\
& & $(2.5)$ & $(1.3)$ & $(1.7)$ & $(1.1)$ & $(1.3)$ \\
Relative inflation rates of & \multirow{2}{*}{0} & 0.01 & $0.01)$ & 0.01 & - & - \\
imported raw materials & & $(1.4)$ & $(1.6)$ & $(1.4)$ & & \\
Change rate of & 0 & 0.04 & 0.03 & 0.03 & - & - \\
tax and price wedge & & $(1.0)$ & $(0.8)$ & $(0.9)$ & & \\
Constant & - & 3.76 & 1.14 & 1.72 & 4.01 & 4.53 \\
& & $(2.9)$ & $(1.0)$ & $(1.9)$ & $(1.2)$ & $(1.2)$ \\
\hline$R^{2}$ adj. & & 0.43 & 0.60 & 0.61 & 0.63 & 0.57 \\
SSR & & 116 & 90 & 92 & 82 & 109 \\
White & & 16.67 & 13.63 & 12.69 & 17.79 & 9.43 \\
& & $(0.73)$ & $(0.25)$ & $(0.31)$ & $(0.40)$ & $(0.22)$ \\
LM(4) & 2.75 & 8.18 & 7.50 & 0.81 & 3.75 \\
& & $(0.73)$ & $(0.09)$ & $(0.11)$ & $(0.94)$ & $(0.44)$ \\
LM(8) & 4.96 & 9.81 & 9.25 & 13.88 & 11.40 \\
& & $(0.76)$ & $(0.28)$ & $(0.32)$ & $(0.08)$ & $(0.18)$ \\
Normality & 43.40 & 65.86 & 97.27 & 0.58 & 10.20 \\
& $(0.00)$ & $(0.00)$ & $(0.00)$ & $(0.75)$ & $(0.01)$ \\
\hline
\end{tabular}

Besides a proper treatment of expectations another problem to be dealt with is to what extent expectations are fully rational. This aspect includes at least two issues. The first may be termed cognitive bias, i.e., whether people know the correct inflation rate and believe it even if it is defined correctly by, say, using hedonic price measures. A good example for a cognitive failure on a large scale was, at least in Germany, the worries about a considerable impact of the introduction of the Euro on inflation in the beginning of the year 2002. Although the Statistical Office reported inflation rates of consumer prices around 2.5 and 1.3 per cent in 2001 and 2002, respectively, (with a falling trend in virtually all months of 2002), ordinary consumers "felt" a tremendous inflationary upturn, the "Teuro" in the local jargon. ${ }^{46}$ Probably people focussed too much on those goods and services with really high price increases (in due course of the Euro) compared with weights representing their actual expenditures. Whatever the psychology behind such a misconception may be, quite a few analysts claim that it contributed to an explanation of the slowdown of consumer expenditures in that year.

The second issue is the question of near-rationality during periods of low inflation. This

\footnotetext{
${ }^{46}$ The T stems from "teuer", that means expensive.
} 
Figure 2: Moving average of inflation rates of consumer prices $1972 / 1$ to $2002 / 2^{a}$ )

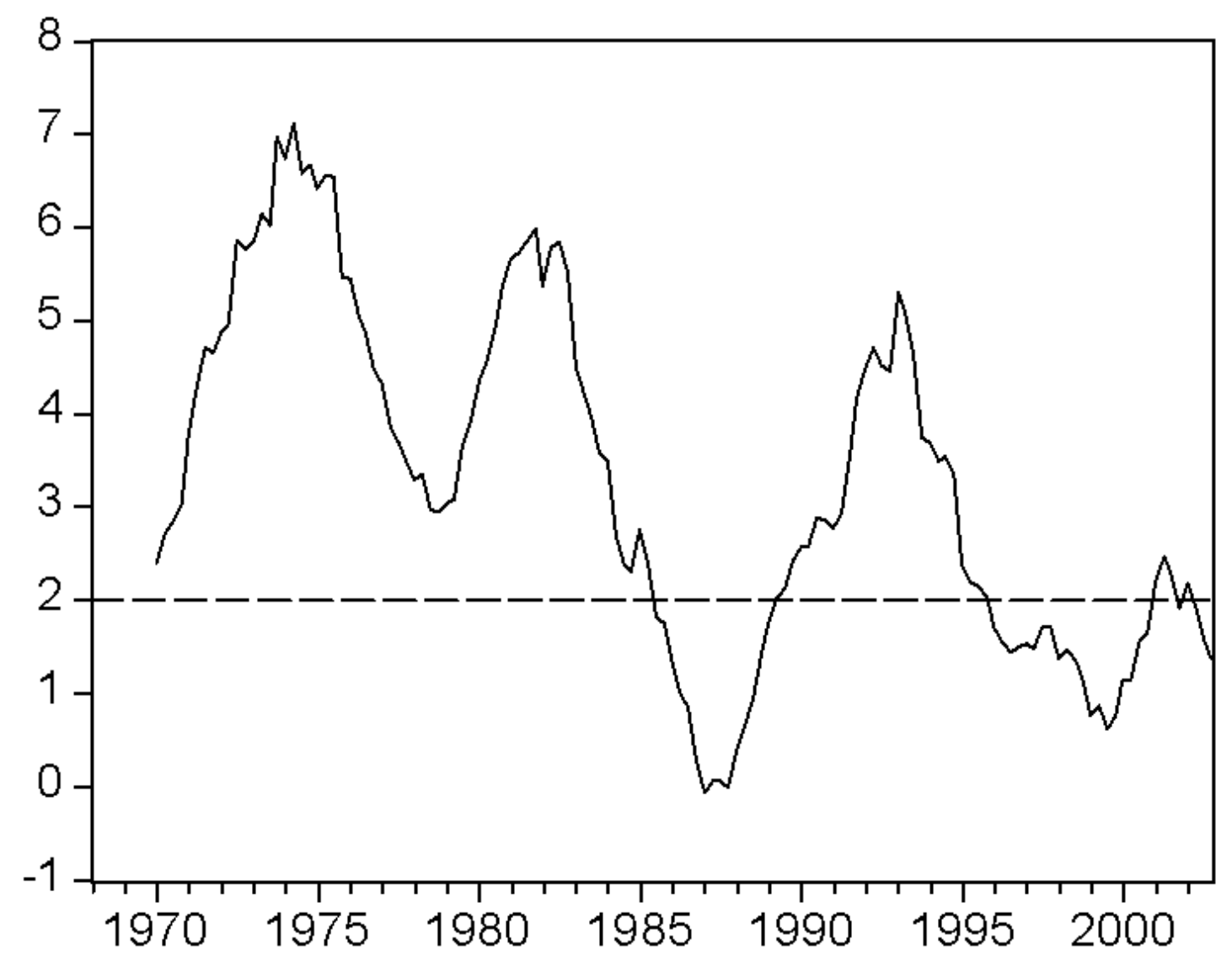

a) Defined as $0.125 \cdot \sum_{i=0}^{7} p_{t-i}^{c}$, where $p_{t}^{c}$ is the actual inflation rate in period $t$.

Source: see notes below table 1 .

question has already been addressed in section 3. If people take inflation into account only if it exceeds some threshold value, then Phillips curve estimates excluding periods of low inflation should yield coefficients on inflation which are significantly higher. ${ }^{47}$ As a first cut at the data, figure 2 displays average inflation rates by consumer prices in the eight-quarter period ending each quarter. To be sure, choosing the type of the moving average of current and past inflation rates is subject to arbitrariness. This objection holds for determining the "low inflation-threshold", too. When we accept the European Central Bank's view (which presumably meets the opinion shared by the Deutsche Bundesbank) that an inflation rate which falls short of 2 per cent p.a. is yet consistent with price stability, this mark may serve as a reasonable guess-estimate for a borderline inflation rate. By this sorting, the quarters from 1972/1 to 1984/4 and 1989/1 to 1995/4 can be classified as "inflation quarters". Hence, we have 74 observations which exclude 22 "no inflation quarters". ${ }^{48}$ In contrast to the study by Akerlof, Dickens and Perry (2000) who classify quarters with inflation rates below 3 per cent as low-inflation

\footnotetext{
${ }^{47}$ See Akerlof, Dickens and Perry (2000).

${ }^{48}$ In light of the high reputation of the Deutsche Bundesbank the result of this classification may come as a surprise.
} 
quarters and those with above 4 per cent as high-inflation quarters, our approach seems to be more ambitious with respect to low inflation. But one should keep in mind that, given their experience with hyperinflations, German people may have been more sensitive with respect to inflation than those in the United States. Anyway, estimates with other figures did not yield substantially different results.

Table 5: Phillips curves for inflation periods ${ }^{a}$ ). Dependent variable: Inflation rate of consumer prices

\begin{tabular}{|l|c|c|c|}
\hline \multirow{2}{*}{ Explanatory variables } & \multirow{2}{*}{ Lags } & \multicolumn{2}{|c|}{ Sample period } \\
\cline { 3 - 4 } & & $1972 / 1-1984 / 4$ & $1972 / 1-1984 / 4$ \\
& $1-6$ & 0.44 & 0.65 \\
& & $(2.6)$ & $(3.4)$ \\
Inflation rates & 1 & -0.80 & -0.77 \\
Unemployment rate (ILO) & & $(2.6)$ & $(3.5)$ \\
Relative inflation rate of & \multirow{2}{*}{0} & 0.01 & - \\
imported raw materials & & $(1.5)$ & \\
Change rate of tax & 0 & 0.13 & 0.15 \\
and price wedge & & $(2.8)$ & $(4.7)$ \\
Time trend & - & 0.04 & 0.04 \\
& & $(1.2)$ & $(2.4)$ \\
Constant & - & 3.82 & 2.17 \\
& & $(2.8)$ & $(2.0)$ \\
\hline$R^{2}$ adj. & 0.58 & 0.63 \\
SSR & & 139 & 184 \\
White & 24.05 & 27.52 \\
& & $(0.4)$ & $(0.4)$ \\
LM(4) & 2.98 & 5.42 \\
& & $(0.57)$ & $(0.25)$ \\
LM(8) & 5.96 & 7.85 \\
& & $(0.65)$ & $(0.45)$ \\
Normality & 0.60 & 3.72 \\
& & $(0.75)$ & $(0.16)$ \\
\hline
\end{tabular}

a) See text and notes at the bottom of table 1 .

Table 5 presents the results for the basic version of an augmented Phillips curve for two sample periods of "inflation quarters", i.e., for 1972/1 to 1984/4 and, in addition, 1989/1 to 1995/4, respectively. For the first sample period, the coefficient of interest drops, whereas for the whole time period of "inflation quarters" it amounts to 0.65 which is somewhat higher compared with those displayed in table 3, columns (1)-(3), but not that much if column (3) of table 1 serves as a reference. ${ }^{49}$ While the regression

\footnotetext{
${ }^{49}$ If the same regression for these "inflation quarters" is reestimated for the whole sample period 1972/1 to 2002/2 (i.e., the version in table 3, col. (3) but without the relative inflation rate of imported
} 
coefficient of the unemployment rate increases, too, relative inflation of imported raw materials lacks significance (although oil price shocks occured in the sample period).

Taken together, the upshot of these estimations is that there is virtually no evidence that the coefficient of lagged inflation rates varies considerably with the extent of inflation. It should be stressed that this verdict is preliminary at best. A more insightful procedure would rest on explicit measures of inflation expectations (perhaps in addition to lagged actual inflation). However, as has been pointed out, the sample period of directly measured inflation expectations starts at 1987 only, and, therefore, a split between inflation and no inflation quarters, respectively, yields an insufficient number of observations.

What can be done, however, is to test whether the coefficient of expected inflation varies positively with inflation. Following Akerlof et al. (2000), this idea has been outlined in section 3. More precisely, the part of the Phillips curve under consideration reads as follows:

$$
p_{t}=\Phi\left(a+b \tilde{p}_{t}\right) p_{t}^{*}+\ldots
$$

where $p_{t}$ and $p_{t}^{*}$ denote actual and expected inflation rates, respectively, and $\tilde{p}_{t}$ is a moving average of current and past inflation rates as displayed in figure 2 . $\Phi$ is the standard cumulative normal distribution and $a, b$ are parameters to be estimated. Using $\Phi$ ensures that the coefficient of expected inflation lies in the 0,1 -interval. The problem with this method is that the coefficient of expected inflation, strictly speaking, cannot be one but may approach this value at best. The data on expected inflation and the specification of the Phillips curve are the same as displayed in table 4, column (3). The Phillips curve employing the expression in equation (17) is estimated by nonlinear methods and yields estimates ( $t$-values in brackets) of $a=0.13(0.1)$ and $b=0.38(0.8)$. The coefficients are far from being significant and, moreover, other explanatory variables also lack significance now. The result with respect to the coefficients $a$ and $b$ changes only slightly no matter what specification of the Phillips curve is chosen (including the square of $\tilde{p}_{t}$ in equation (17) rather than $\tilde{p}_{t}$ ). Again, this result is preliminary at best, given the short sample period (from 1987/1 to 2000/4, i.e., 56 observations) and the question whether the direct measure of $p_{t}^{*}$ is appropriate.

Finally, an attempt is made to estimate a time-varying NAIRU. As has been outlined before, the motivation to join such a "state of the art-NAIRU" estimation is that our supply shock variables may not capture all shocks or institutional changes which influence inflation and unemployment. The German labor market, in particular, is subject to numerous institutional barriers which cloud the issues. For example, they may operate like ratchet effects which, after a recovery, prevent unemployment from returning to pre-recession or pre-shock levels. Indeed, as a comparison of unemployment rates between (West) Germany and, say, the United States reveals, the real unemployment problem in Germany consists, by and large, of unemployment rates increasing step wise and never declining to the status quo ex ante. This stands in marked contrast to the experience in the United States.

raw materials) the sum of coefficients of lagged inflation rates amounts to 0.66 which is nearly identical with the respective figure in the above regression. 
In spite of this motivation, estimating a (time-varying) NAIRU means walking on a shaky ground, to put it mildly. To some extent, it reminds us of a symposium on the well-known writer Homer. The attending classicists strongly disagreed on whether Homer lived at all, but they unanimously agreed that he was blind.

Be that as it may, the methodological tool applied was discussed at some length in section 5.4. Suffice it to recall that the estimation is based on the Kalman filter method. ${ }^{50}$ The confidence intervals are estimated using the residual-based bootstrap procedure. The equation in question is displayed in column (2) of table 3 with the supply sift variables assumed to be zero, i.e., a time-varying "no-shock-NAIRU" is under consideration. Since the coefficient associated with lagged inflation is well below unity the NAIRU depends on a given inflation rate (see end of section 3) which is set to 0.5 per cent each quarter (i.e., roughly 2 per cent p.a. as discussed before). Figure 3 displays the results. Note that the unemployment rate in this figure is based on the definition by the German Federal Labor Office in order to make the results comparable with estimates obtained in previous studies. Moreover, estimates with the unemployment rate based on the ILO definition yielded an (unplausibly) high NAIRU for the beginnings of the 1980's, such as slightly more than 6 per cent. This result already casts doubts on the reliability of NAIRU estimates. Taken at face value, the NAIRU in figure 3 is rising rather steadily over time but has flattened since the end of the 1990s with a NAIRU amounting to roughly 10 per cent for Germany as a whole. An accompanying study for West Germany winds up with an 8 per cent NAIRU for 1998 (Franz (2003)). The confidence intervals appear to be rather narrow compared with the estimates for the U.S. To some extent the narrow and rather symmetric estimated confidence intervals may be due to biased residuals which are subject to first order autocorrelation. Both the slightly unrealistic high value of the NAIRU at the end of the observation period and the doubtfully narrow confidence intervals render these estimates rather questionable. With respect to the estimation of the time-varying coefficients, we also employed the procedure by Schlicht (2003) described briefly in section 5.4. As a result, the development of the NAIRU displays a bit of a less smooth series (but not a totally erratic one) and winds up with approximately the same figure of the NAIRU for 2002 (but with considerably higher values before compared with the Kalman-method).

\section{Epilogue}

By any method, simple or complex, the NAIRU is very hard to determine. Even worse, the whole NAIRU idea may be seriously damaged if the joint behavior of inflation, wage rises and unemployment has deteriorated. As to the simple method, an inspection of a scatter diagram of inflation and unemployment already displays that there is no such thing like a unique vertical Phillips curve. Perhaps this figure resembles a shifting set of short-run Phillips curves. A more complex method is to estimate Phillips curves preferably with time-varying parameters and confidence intervals for the estimated NAIRU. At the risk of exaggerating the case: not very much of all attempts really worked. Estimates of conventional Phillips curves suffer from serious flaws and the

\footnotetext{
${ }^{50}$ The estimates are carried out using the program package TSP 4.5.
} 
Figure 3: Time-varying NAIRU for Germany ${ }^{a}$

Time varying NAIRU for Germany

(National Unemployment Rate)

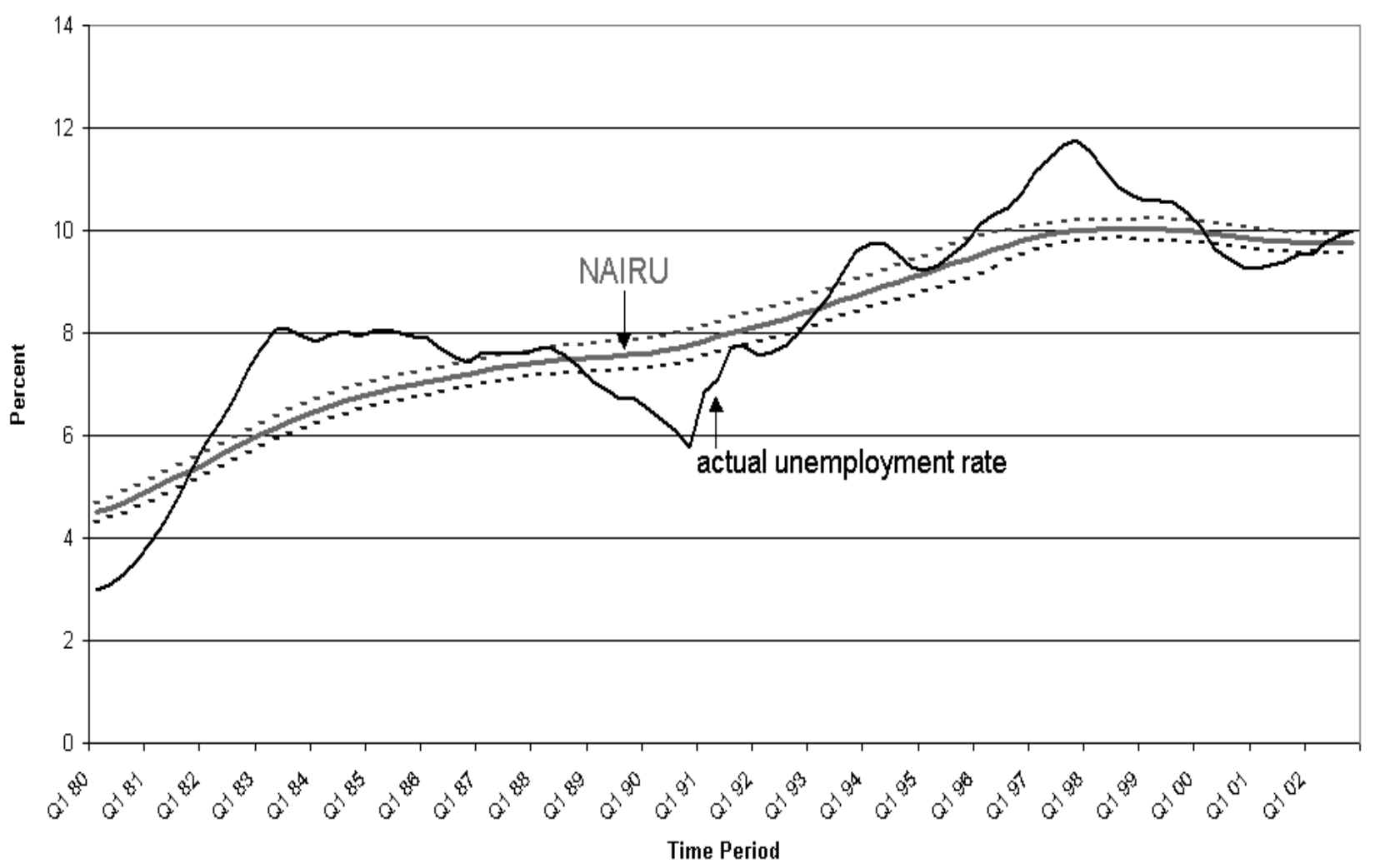

a) 1980I-1991IV: West Germany; Germany afterwards. See text for details.

time-varying NAIRU is not only subject to considerable arbitrariness but is also vulnerable to criticism put forward by Solow almost two decades ago: "A natural rate that hops around from one triennium to another under the influence of unspecified forces, including past unemployment rates, is not 'natural' at all. 'Epiphenomenal' would be a better adjective; look it up". ${ }^{51}$ To put it differently, yet taking the risk of an oversimplification: What has been estimated with a highly sophisticated machinery is simply the trend unemployment rate. If so, this can be carried out much easier and within a few minutes, just by using an HP filter.

But one should be careful not to throw out the baby with the bathwater. Unemployment matters in explaining inflation. Keeping the unemployment rate one percentage point lower will result in an inflation rate increasing around 0.5 to 1.0 percentage points ceteris paribus and after all adjustments have taken place. This is large enough a number to command attention. The failure of getting a more empirically convinc-

\footnotetext{
${ }^{51}$ Solow (1986), p. S33, italic words ibidem. For the sake of convenience, Webster's New Collegiate Dictionary defines an epiphenomenon as "a secondary phenomenon accompanying another and caused by it".
} 
ing estimate of a (time-varying) NAIRU may perhaps stem from the fact that much more efforts must be undertaken to estimate adequate price and wage equations. The problem is that many influences especially on wage formation are qualitative in nature and therefore extremely difficult to account for. In the words of N.G. Mankiw (2001): "Research areas attract interest when there are outstanding scientific puzzles to be solved. The failure to produce a dynamic relationship between inflation and unemployment that is derived from first principles and that fits the facts is surely such a puzzle" (p. C59).

To this end, the question arises whether the NAIRU is (still) a useful tool to frame policy discussions despite of all the uncertainty surrounding its level and direction of change. The answer is "no", unless the NAIRU is combined with other diagnostics of the economists' toolkit.

In summing up, this is my last paper on the NAIRU (part I, perhaps). 


\section{References}

Akerlof, G.A. (2002), Behavioral Macroeconomics and Macroeconomic Behavior, American Economic Review 92(3), 411-433.

Akerlof, G.A., W.T. Dickens and G.L. Perry (2000), Near-Rational Wage and Price Setting and the Long-Run Phillips Curve, Brookings Papers on Economic Activity 1:2000, 1-60.

Ball, L. and N.G. Mankiw (2002), The NAIRU in Theory and Practice, Journal of Economic Perspectives 16(4), 115-136.

Banerjee, A., J.J. Dolado and R. Mestre (1998), Error-Correction Mechanism Test for Cointegration in a Single-Equation Framework, Journal of Time Series Analysis 19, 267-283.

Batchelor, R.A. and A.B. Orr (1988), Inflation Expectations Revisited, Economica $55,317-331$.

Beyer, A. and R.E.A. Farmer (2002), Natural Rate Doubts, European Central Bank, Working Paper No. 121, Frankfurt/Main.

Carlin, W. and D. Soskice (1990), Macroeconomics and the Wage Bargain, Oxford (University Press).

Carlson, J.A. and M. Parkin (1975), Inflation Expectations, Economica 42, 123137.

Driver, R.L., J.V. Greenslade and R.G. Pierse (2003), The Role of Expectations in Estimates of the NAIRU in the United States and the United Kingdom, Bank of England, Working Paper No. 180, London.

Eckstein, O. and R. Brinner (1972), The Inflation Process in the United States, Joint Economic Committee of the Congress of the United States, Government Printing Office, Washington D.C. (information taken from Akerlof et al.).

Efron, B. (1982), The Jackknife, the Bootstrap and other Resampling Plans, Philadelphia (SIAM).

Fabiani, S. and R. Mestre (2001), A System Approach for Measuring the Euro Area NAIRU, European Central Bank, ECB Working Paper No. 65, Frankfurt/Main.

Fabiani, S. and J. Morgan (2003), Aggregation and Euro Area Phillips Curve, European Central Bank, Working Paper No. 213, Frankfurt/Main.

Fair, R.C. (2000), Testing the NAIRU Model for the United States, Review of Economics and Statistics 82(1), 64-71.

Forsells, M. and G. Kenny (2002), The Rationality of Consumers' Inflation Expectations: Survey-Based Evidence for the Euro Area, European Central Bank, Working Paper No. 163, Frankfurt/Main. 
Franz, W. (1984), Inflation und interindustrielle Lohnstruktur, IFO-Studien 30(2), 81-106.

Franz, W. (1987), Hysteresis, Persistence and the NAIRU: An Empirical Analysis for the Federal Republic of Germany, in: R. Layard and L. Calmfors (eds.), The Fight Against Unemployment, Cambridge, Mass. (MIT-Press), 91-122.

Franz, W. (2001), Neues von der NAIRU?, Jahrbücher für Nationalökonomie und Statistik 221(3), 256-284.

Franz, W. (2003), It's Always Nice to Meet an Old Friend: Reflections on the NAIRU and New Estimates, in: R. Pethig and M. Rauscher (eds.), Challenges to the World Economy, Festschrift for Horst Siebert, Berlin (Springer), 45-53.

Franz, W. and R.J. Gordon (1993), German and American Wage and Price Dynamics: Differences and Common Themes, European Economic Review 37(4), 719-762.

Franz, W. and F. Pfeiffer (2002), The Rationale for Wage Rigidity: Survey Evidence from German and US Firms, Centre for European Economic Research (ZEW), Discussion Paper No. 02-60, Mannheim (download from: ftp://ftp.zew.de/pub/zew-docs/dp/dp0260.pdf).

Franz, W. and K. Siebeck (1991), A Theoretical and Econometric Analysis of Structural Unemployment in Germany: Reflections on the Beveridge Curve, in: W. Franz (ed.), Structural Unemployment, Heidelberg (Physica), 1-58.

Gerberding, C. (2001), Der Informationsgehalt von Umfragedaten zur erwarteten Preisentwicklung für die Geldpolitik, Deutsche Bundesbank, Volkswirtschaftliches Forschungszentrum, Diskussionspapier 09/01, Frankfurt/Main.

Gordon, R.J. (1997), The Time-Varying NAIRU and its Implications for Economic Policy, Journal of Economic Perspectives 11(1), 11-32.

Gordon, R.J. (1998), Foundations of the Goldilocks Economy: Supply Shocks and the Time-Varying NAIRU, Brookings Paper of Economic Activity 1998:2, 297346.

Graham, L. and D.J. Snower (2002), The Return of the Long-Run Phillips Curve, Institute for the Study of Labor (IZA), Discussion Paper No. 646, Bonn.

Greenslade, J.V., R.G. Pierse and J. Saleheen (2003), A Kalman Filter Approach to Estimating the UK NAIRU, Bank of England, Working Paper No. 179, London.

Gruen, D., A. Pagan and C. Thompson (1999), The Phillips Curve in Australia, Journal of Monetary Economics 44(2), 223-258.

Harvey, A.C. (1993), Time Series Models, 2nd ed., New York (Harvester/Wheatsheaf).

Hassler, U. (2002), Dickey-Fuller Cointegration Tests in the Presence of Regime Shifts at Known Time, Allgemeines Statistisches Archiv 86, 263-276. 
Laubach, Th. (2001), Measuring the NAIRU: Evidence from Seven Economies, Review of Economics and Statistics 83(2), 218-231.

MacKinnon, J.G. (1991), Critical Values for Cointegration Tests, in: R.F. Engle and C.W.J. Granger (eds.), Long-Run Economic Relationships: Readings in Cointegration, Oxford (University Press), 267-276.

Mankiw, N.G. (2001), The Inexorable and Mysterious Tradeoff between Inflation and Unemployment, Economic Journal 111 (No. 471), C45-C61.

Reckwerth, J. (1997), Der Zusammenhang zwischen Inflation und Output in Deutschland unter besonderer Berücksichtigung der Inflationserwartungen, Deutsche Bundesbank, Volkswirtschaftliche Forschungsgruppe, Diskussionspapier 5/97, Frankfurt/Main.

Richardson, P., L. Boone, C. Giorno, M. Meacci, D. Rae, and D. Turner (2000), The Concept, Policy Use and Measurement of Structural Unemployment: Estimating a Time Varying NAIRU Across 21 OECD Countries, OECD, Economics Department Working Paper No. 250, Paris.

Sargent, T.J. (1971), A Note on the "Accelerationist" Controvery, Journal of Money, Credit and Banking 3(3), 721-725.

Schlicht, E. (2003), Estimating Time-Varying Coefficients with the VC Program, mimeo, University of Munich, www.lrz.de/ ekkehart.

Schreiber, S. and J. Wolters (2002), What's Wrong with the (German) NAIRU?, Diskussionsbeiträge des Fachbereichs Wirtschaftswissenschaft der Freien Universität Berlin Nr. 2002/8, Berlin.

Snower, D.J. and M. Karanassou (2002), An Anatomy of the Phillips Curve, Institute for the Study of Labor (IZA), Discussion Paper No. 635, Bonn.

Solow, R.M. (1986), Unemployment: Getting the Questions Right, Economica 53 (Supplement 1986), S23-S34.

Staiger, D., J.H. Stock and M.W. Watson (1997a), How Precise are the Estimates of the Natural Rate of Unemployment?, in: C.D. Romer and D.H. Romer (eds.), Reducing Inflation. Motivation and Strategy, Chicago (University Press), $195-242$.

Staiger, D., J.H. Stock and M.W. Watson (1997b), The NAIRU, Unemployment and Monetary Policy, Journal of Economic Perspectives 11(1), 33-49.

Stiglitz, J.E. (1997), Reflections on the Natural Rate Hypothesis, Journal of Economic Perspectives 11(1), 3-10. 